Provided for non-commercial research and education use. Not for reproduction, distribution or commercial use.

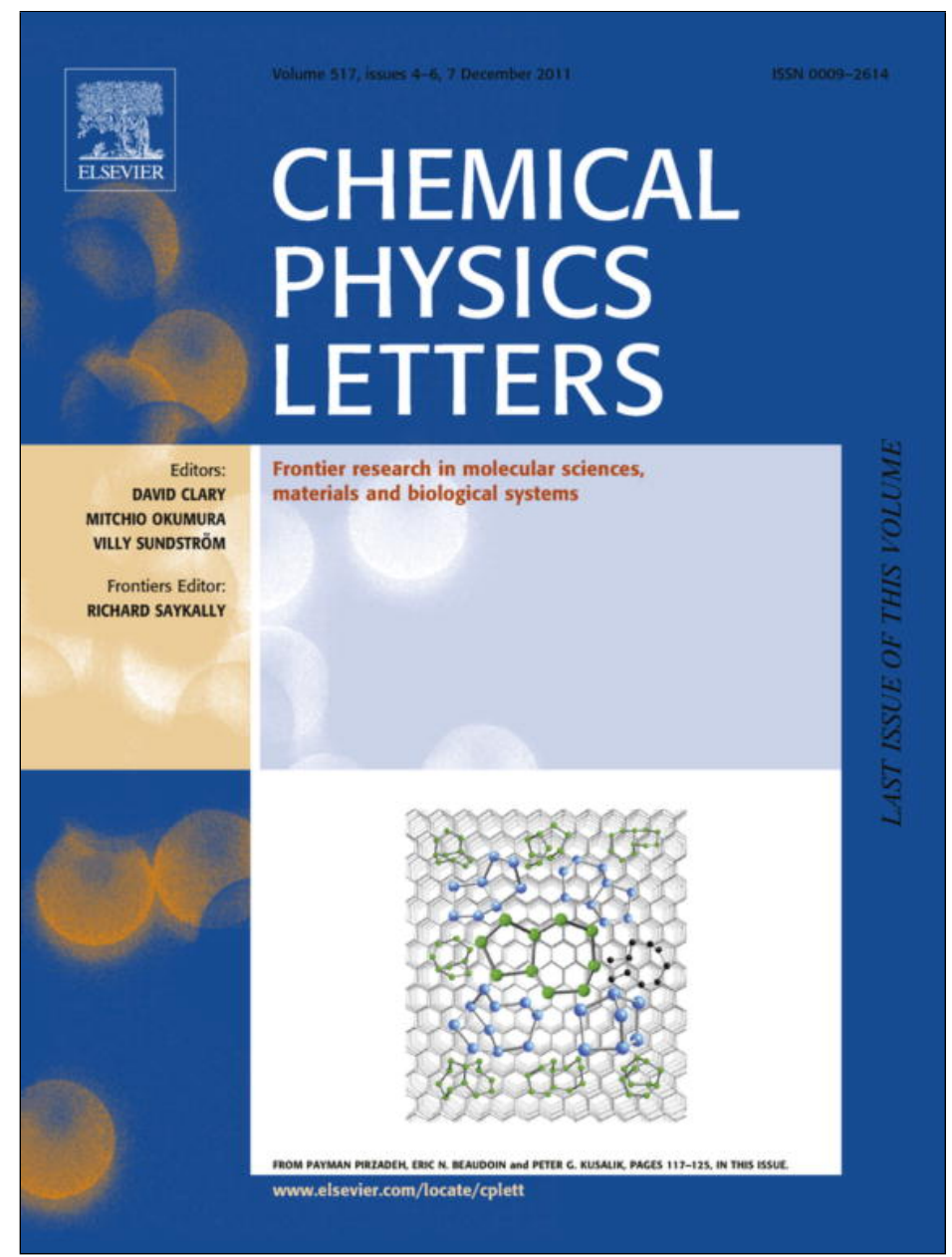

This article appeared in a journal published by Elsevier. The attached copy is furnished to the author for internal non-commercial research and education use, including for instruction at the authors institution and sharing with colleagues.

Other uses, including reproduction and distribution, or selling or licensing copies, or posting to personal, institutional or third party websites are prohibited.

In most cases authors are permitted to post their version of the article (e.g. in Word or Tex form) to their personal website or institutional repository. Authors requiring further information regarding Elsevier's archiving and manuscript policies are encouraged to visit:

http://www.elsevier.com/copyright 


\title{
Low-temperature cross polarization in view of enhancing dissolution Dynamic Nuclear Polarization in NMR
}

\author{
Sami Jannin ${ }^{\mathrm{a}, *}$, Aurélien Bornet ${ }^{\mathrm{a}}$, Sonia Colombo ${ }^{\mathrm{b}, \mathrm{c}}$, Geoffrey Bodenhausen ${ }^{\mathrm{a}, \mathrm{d}, \mathrm{e}, \mathrm{f}}$ \\ a Institut des Sciences et Ingénierie Chimiques, Ecole Polytechnique Fédérale de Lausanne (EPFL), Batochime, CH-1015 Lausanne, Switzerland \\ ${ }^{\mathrm{b}}$ Centro Ricerche Bracco, Bracco Imaging Spa, Via Ribes 5, I-10010 Colleretto Giacosa (TO), Italy \\ ${ }^{\mathrm{c}}$ Dept. of Experimental Physics, University of Torino, Via P. Giuria 1, I-10100 Torino, Italy \\ ${ }^{\mathrm{d}}$ Département de Chimie, Ecole Normale Supérieure, 24 Rue Lhomond, 75231 Paris Cedex 05, France \\ ${ }^{\mathrm{e}}$ Université Pierre-et-Marie Curie, Paris, France \\ ${ }^{\mathrm{f}}$ CNRS, UMR 7203, Paris, France
}

\section{A R T I C L E I N F O}

\section{Article history:}

Received 31 August 2011

In final form 21 October 2011

Available online 26 October 2011

\begin{abstract}
A B S T R A C T
Dynamic Nuclear Polarization (DNP) induced by saturation of ESR transitions of TEMPO at $1.2 \mathrm{~K}$ and 3.35 $\mathrm{T}$ is characterized by build-up rates that are typically 5 times faster for protons than for the carboxylic carbon-13 in acetate. We show that cross polarization from protons to carbon-13 allows one to achieve a polarization $P\left({ }^{13} \mathrm{C}\right)>20 \%$ in less than $10 \mathrm{~min}$, twice as much as has been previously reported, in one-fifth of the time. This should open the way to an unprecedented improvement in the efficiency of dissolution DNP.
\end{abstract}

(c) 2011 Elsevier B.V. All rights reserved.
So far, most NMR or MRI studies based on dissolution DNP [1] have focused on nuclear spins such as ${ }^{13} \mathrm{C},{ }^{15} \mathrm{~N},{ }^{89} \mathrm{Y}$, etc., that have long nuclear spin-lattice relaxation times $T_{1}$ in the liquid state. Long $T_{1}$ 's are mandatory to study slow chemical reactions [2] or metabolic processes [3]. Unfortunately the polarization build-up times $\tau_{\mathrm{DNP}}$ of such spins can be excessively long, typically on the order of $10-60 \mathrm{~min}[4,5]$. Although the more abundant protons usually have much shorter $\tau_{\mathrm{DNP}}$ at low temperatures, they also tend to have much shorter $T_{1}$ 's in the liquid state, so that protons appear to be of limited interest to monitor slow reactions. However, it has recently been shown that proton hyper-polarization can be stored in the form of Long Lived States (LLS) [6-8] which can have lifetimes on the order of $100 \mathrm{~s}$. This can be achieved by semi-selective inversion using suitable radio-frequency ( $r f$ ) pulses at high field, followed by shuttling the sample to low field [9]. Nevertheless, since many chemically and biologically relevant molecules cannot support LLS that require a pair of reasonably isolated protons, it may be assumed that molecules containing ${ }^{13} \mathrm{C}$ or ${ }^{15} \mathrm{~N}$ spins with long $T_{1}$ 's as in carbonyl groups will remain popular for dissolution-DNP experiments.

We demonstrate in this Communication that cross polarization (CP) [10] from protons to low-gamma nuclei such as ${ }^{13} \mathrm{C}$ can be carried out efficiently at $T=1.2 \mathrm{~K}$ and $B_{0}=3.35 \mathrm{~T}$. Since the build-up of proton polarization by DNP using microwave saturation of the electron spin resonance (ESR) transitions of the

\footnotetext{
* Corresponding author. Address: Institut des Sciences et Ingénierie Chimiques, Ecole Polytechnique Fédérale de Lausanne (EPFL), BCH 1534 (Bâtiment de chimie UNIL), CH-1015 Lausanne, Switzerland. Fax: +41 216939435.

E-mail address: sami.jannin@epfl.ch (S. Jannin).
}

free radical 2,2,6,6-tetramethyl-1-piperidinyloxy (TEMPO) is fast, one can quickly obtain intense ${ }^{13} \mathrm{C}$ signals after cross-polarization. The ESR lineshape of TEMPO displays inhomogeneous broadening dominated by $g$-anisotropy, $g_{\mathrm{xx}}=2.0096, g_{\mathrm{yy}}=2.0065, g_{\mathrm{zz}}=2.0023$, so that the ESR linewidth $\left(2 \sqrt{ } \mu_{2}=230 \mathrm{MHz}\right)$ exceeds NMR Larmor frequencies at $B_{0}=3.35 \mathrm{~T}$. With appropriate radical concentrations (ca. $30 \mathrm{mM}$ TEMPO) one obtains large electron-electron dipolar couplings $D$ (ca. $10 \mathrm{MHz}$ ) allowing a unique spin temperature to be established in the electron dipolar spin bath. With suitable microwave irradiation $\left(P_{\mu \mathrm{w}}=30 \mathrm{~mW}, f_{\mu \mathrm{w}}=93.9 \mathrm{G} \mathrm{Hz}\right)$, the dominant DNP build-up mechanism is the so-called Thermal Mixing (TM) effect [11] which ultimately confers a common temperature $T_{\mathrm{s}} \approx 8.5 \mathrm{mK}$ to all nuclear spins with $I=1 / 2$ in the sample. The nuclear spin polarization is given by:

$P=\tanh \left(\frac{h \omega_{I}}{2 k_{B} T_{S}}\right)$

where $\omega_{I}$ is the nuclear Larmor frequency. A spin temperature $T_{S}=8.5 \mathrm{mK}$ is equivalent to polarizations $P\left({ }^{1} \mathrm{H}\right) \approx 0.4$ and $P\left({ }^{13} \mathrm{C}\right) \approx 0.1$. The build-up rates of DNP are much faster for protons than for low-gamma nuclei [5]. Figure 1 shows DNP build-up curves of ${ }^{1} \mathrm{H}$ and ${ }^{13} \mathrm{C}$ magnetization, measured at $1.2 \mathrm{~K}$ at regular intervals with small flip angle pulses ( $\beta=1^{\circ}$ and $5^{\circ}$, respectively). A $1 \mathrm{M}$ solution of $1{ }^{13} \mathrm{C}$ enriched sodium acetate dissolved in a deuterated water/ethanol mixture $(67: 33 \mathrm{v} / \mathrm{v})$ was doped with $30 \mathrm{mM}$ TEMPO to form glassy beads in liquid nitrogen. At $1.2 \mathrm{~K}$, the build-up time-constant of the proton magnetization $\tau_{\mathrm{DNP}}\left({ }^{1} \mathrm{H}\right)=81 \mathrm{~s}$ is ten times less than $\tau_{\mathrm{DNP}}\left({ }^{13} \mathrm{C}\right)=890 \mathrm{~s}$, and, as expected by thermal mixing theory, the steady-state DNP polarization is ca. 4 times 

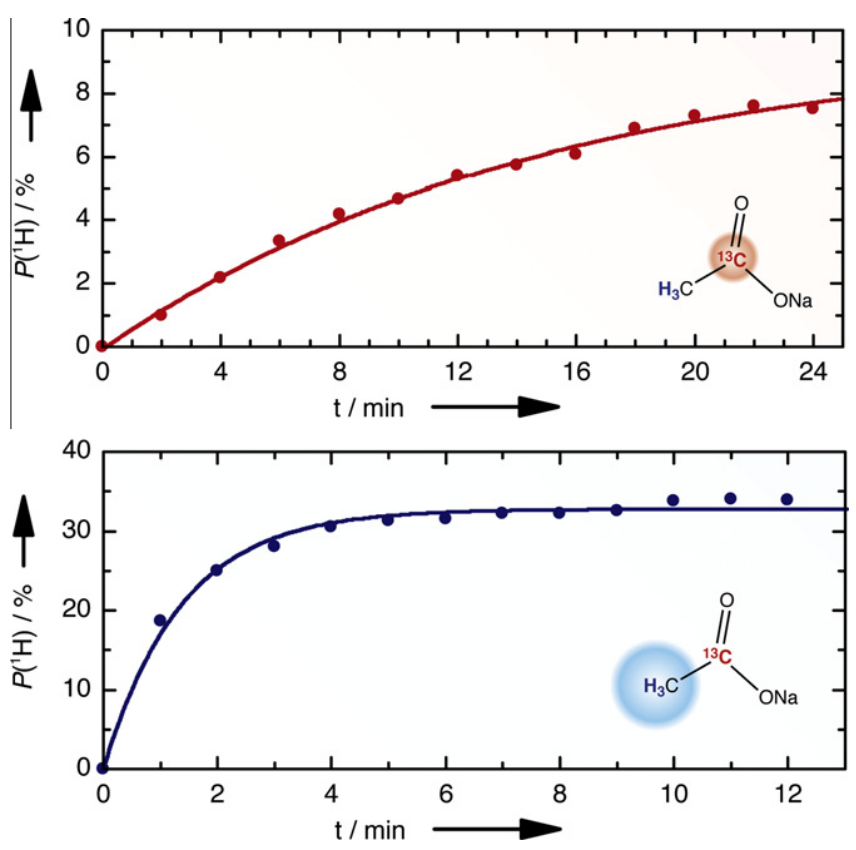

Figure 1. DNP build-up curves measured for ${ }^{1} \mathrm{H}$ and ${ }^{13} \mathrm{C}$ without cross-polarization at $T=1.2 \mathrm{~K}$ and $B_{0}=3.35 \mathrm{~T}$ with DNP using $P_{\mu \mathrm{w}}=30 \mathrm{~mW}$ and $f_{\mu \mathrm{w}}=93.9 \mathrm{GHz}$. The build-up times are $\tau_{\mathrm{DNP}}\left({ }^{1} \mathrm{H}\right)=81 \mathrm{~s}$ and $\tau_{\mathrm{DNP}}\left({ }^{13} \mathrm{C}\right)=890 \mathrm{~s}$, and the maximum achieved polarizations are $P\left({ }^{13} \mathrm{C}\right) \approx 0.095$ and $P\left({ }^{1} \mathrm{H}\right) \approx 0.34$.

greater for protons than for carbon-13, i.e., $P\left({ }^{1} \mathrm{H}\right) \approx 0.4$ and $P\left({ }^{13} \mathrm{C}\right) \approx 0.1$.

With a custom-built doubly tuned NMR probe coupled to a solid-state Bruker NMR spectrometer allowing simultaneous $r f$ irradiation of ${ }^{1} \mathrm{H}$ and ${ }^{13} \mathrm{C}, \mathrm{CP}$ experiments were carried out using a home-built polarizer [4]. The design of the tuning and matching capacitors and the immersion of the horizontal solenoidal $r f$ coil that contains the DNP sample in the liquid helium bath at $1.2 \mathrm{~K}$ provide efficient cooling and high arching limit. It should be noted that the $r f$ circuitry must be very efficient to avoid heating the sample, and should display good rejection between the two channels (higher than $30 \mathrm{~dB}$ for both ${ }^{1} \mathrm{H}$ and ${ }^{13} \mathrm{C}$ in our case). The two transmitters can generate $r f$ field amplitudes of $55 \mathrm{kHz}$ each with only about 14 and $22 \mathrm{~W}$ for the ${ }^{1} \mathrm{H}$ and ${ }^{13} \mathrm{C}$ channels, respectively (both $Q$ factors are equal to 130). Conventional CP has been combined with DNP and magic-angle spinning (MAS) at temperatures near $100 \mathrm{~K}[12,13]$. In the Dissolution DNP approach, one should restore the ${ }^{13} \mathrm{C}$ and ${ }^{1} \mathrm{H}$ polarizations by flip-back pulses [14] after $\mathrm{CP}$ contact to preserve the maximum polarization before dissolution (Figure 2).

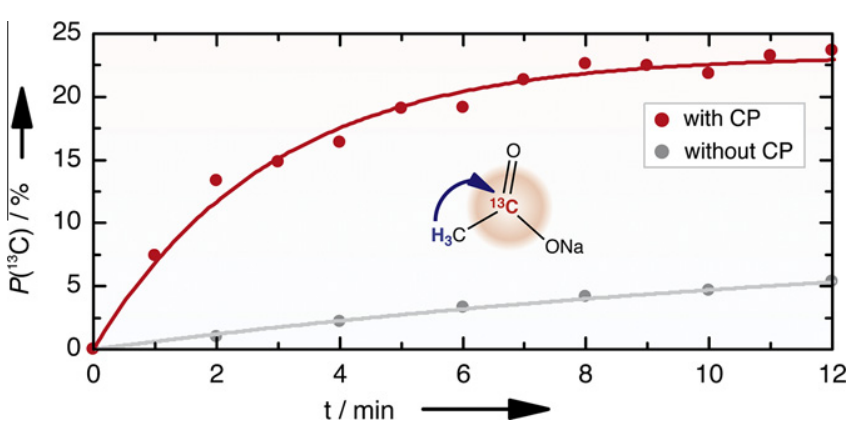

Figure 3. DNP build-up of the ${ }^{13} \mathrm{C}$ polarization, measured without $\mathrm{CP}$ with short $5^{\circ}$ observation pulses (bottom gray curve), and with CP (top red curve) as shown in Figure 2.

Figure 3 shows the DNP build-up curve of the ${ }^{13} \mathrm{C}$ polarization in $1{ }^{13} \mathrm{C}$ labeled acetate with and without $\mathrm{CP}$. The latter experiment used $5^{\circ}$ pulses repeated every 2 minutes, while CP was performed as shown in Figure 2 with the following parameters: $r f$ field amplitudes $v_{1}\left({ }^{1} \mathrm{H}\right)=v_{1}\left({ }^{13} \mathrm{C}\right)=55 \mathrm{kHz}$, contact time $\tau_{2}=1 \mathrm{~ms}$, delay prior to short observation pulse $\tau_{3}=50 \mathrm{~ms},{ }^{13} \mathrm{C}$ nutation angle $\beta=5^{\circ}$, acquisition time $5 \mathrm{~ms}$, and recovery delay $\tau_{1}=0$. A maximum ${ }^{13} \mathrm{C}$ spin polarization of $P\left({ }^{13} \mathrm{C}\right)=23 \%$ was achieved with a build-up time $\tau_{\mathrm{DNP}}{ }^{\mathrm{CP}}\left({ }^{13} \mathrm{C}\right)=170 \mathrm{~s}$ when using $\mathrm{CP}$, whereas without CP only $P\left({ }^{13} \mathrm{C}\right)=9.5 \%$ could be achieved with $\tau_{\mathrm{DNP}}\left({ }^{13} \mathrm{C}\right)=890 \mathrm{~s}$. This result could theoretically be improved, with an optimal $\mathrm{CP}$ efficiency, to $P\left({ }^{13} \mathrm{C}\right)=P\left({ }^{1} \mathrm{H}\right)=40 \%$ and $\tau_{\mathrm{DNP}}{ }^{\mathrm{CP}}\left({ }^{13} \mathrm{C}\right)=\tau_{\mathrm{DNP}}\left({ }^{1} \mathrm{H}\right)=$ $81 \mathrm{~s}$.

In conclusion, we have demonstrated the virtues of combining cross-polarization (CP) with DNP experiments at low temperatures. The $\mathrm{CP}$ scheme provides a way to efficiently polarize ${ }^{13} \mathrm{C}$ nuclear spins from protons which benefit from a rapid DNP build-up. The maximum ${ }^{13} \mathrm{C}$ polarization is more than doubled while the build up rate is enhanced by a factor 5.2. We believe that further improvement in hardware (saddle coils that are better adapted to rapid dissolution, higher $r f$ amplitudes, faster $r f$ power and phase switching times), sample preparation (e.g., partial deuteration of the solvent, optimization of the radical concentration) and pulse sequence design (e.g., adiabatic variants of $\mathrm{CP}[15])$ may lead to higher enhancements. CP for other ${ }^{13} \mathrm{C}$ labeled compounds that are of interest for in vivo MRI studies shows similar performances. Thus, $1-{ }^{13} \mathrm{C}$ sodium pyruvate gives a twofold enhancement with respect to direct DNP of ${ }^{13} \mathrm{C}$. Dissolution-DNP combined with CP at higher fields [16-18] should yield even higher polarizations $P\left({ }^{13} \mathrm{C}\right)$. CP from protons to very low-gamma spins $\left({ }^{15} \mathrm{~N},{ }^{6} \mathrm{Li},{ }^{89} \mathrm{Y}\right.$, etc.) is also expected to yield substantial enhancements.

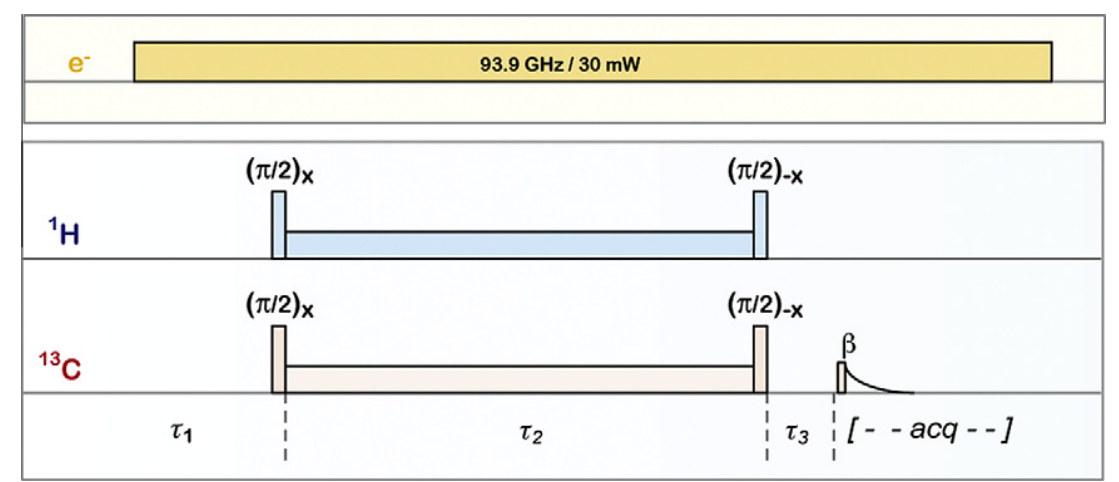

Figure 2. $\mathrm{CP}$ pulse sequence used for enhancing the ${ }^{13} \mathrm{C}$ spin polarization. Both ${ }^{1} \mathrm{H}$ and ${ }^{13} \mathrm{C}$ spin polarizations are restored after $\mathrm{CP}$ by flip-back pulses [14]. 


\section{Acknowledgments}

The authors are indebted to Roberto Melzi, Marc Caporini and Martial Rey for valuable assistance. This work was supported by the Swiss National Science Foundation (grant 200020-124694), the Ecole Polytechnique Fédérale de Lausanne (EPFL), the Swiss Commission for Technology and Innovation (CTI) (grant 9991.1 PFIW-IW), and the French CNRS.

\section{References}

[1] J.H. Ardenkjaer-Larsen et al., Proc. Natl Acad. Sci. USA 100 (2003) 10158.

[2] P. Miéville, S. Jannin, L. Helm, G. Bodenhausen, J. Am. Chem. Soc. 132 (2010) 5006

[3] K. Golman, R. In't Zandt, M. Thaning, Proc. Natl Acad. Sci. USA 103 (2006) 11270

[4] A. Comment et al., Concepts Magn. Reson. Part B 31B (2007) 255.

[5] F. Kurdzesau, B. van den Brandt, A. Comment, P. Hautle, S. Jannin, J.J. van der Klink, J.A. Konter, J. Phys. D 41 (2008) 155506.
[6] M. Carravetta, O.G. Johannessen, M.H. Levitt, Phys. Rev. Lett. 92 (2004) 153003.

[7] P.R. Vasos et al., Proc. Natl Acad. Sci. USA 106 (2009) 18475.

[8] P. Ahuja, R. Sarkar, S. Jannin, P.R. Vasos, G. Bodenhausen, Chem. Commun. 46 (2010) 8192.

[9] A. Bornet, S. Jannin, G. Bodenhausen, Chem. Phys. Lett. 512 (2011) 151.

10] S.R. Hartmann, E.L. Hahn, Phys. Rev. 128 (1962) 2042.

[11] A. Abragam, M. Goldman, Rep. Prog. Phys. 41 (1978) 395

[12] G.J. Gerfen, L.R. Becerra, D.A. Hall, R.G. Griffin, R.J. Temkin, D.J. Singel, J. Chem. Phys. 102 (1995) 9494.

[13] T. Maly, A.-F. Miller, R.G. Griffin, ChemPhysChem 11 (2010) 999.

[14] J. Tegenfeldt, U. Haeberlen, J. Magn. Reson. 36 (1979) 453.

[15] A.J. Pérez Linde, Application of Cross Polarisation Techniques to Dynamic Nuclear Polarisation Dissolution Experiments, in: School of Physics and Astronomy, University of Nottingham, 2010.

[16] D.J. Nicholas, W.G. Williams, P.H.T. Banks, D.A. Cragg, Nucl. Instrum. Methods 87 (1970) 301

[17] G. Hartmann, D. Hubert, S. Mango, C.C. Morehouse, K. Prog, Nucl. Instrum. Methods 106 (1973) 9.

[18] S. Jannin, A. Comment, F. Kurdzesau, J.A. Konter, P. Hautle, B. van den Brandt J.J. van der Klink, J. Chem. Phys. 128 (2008) 241102. 